\title{
PERAN SUPERVISI KEPALA MADRASAH DAN KUALIFIKASI AKADEMIK DALAM MENINGKATKAN KOMPETENSI GURU
}

\author{
Yuda Pranpantja ${ }^{1}$; Evi Satispi ${ }^{2}$; Retnowati WD Tuti ${ }^{3}$ \\ Magister Teknologi Fakultas Ilmu Pendidikan ${ }^{1}$; Magister Ilmu Administrasi, Universitas \\ Muhammadiyah Jakarta ${ }^{23}$ \\ yudhantja@gmail.com¹; evi.satispi@umj.ac.id²; retnowatiwdtuti@umj.ac.id ${ }^{3}$
}

\begin{abstract}
The low competence of teachers in Indonesia can be seen from the feasibility of teaching teachers. Evidence of low teacher professionalism can also be seen from the number of teachers who do not master various competencies. For example, there are still many teachers experiencing problems in implementing various learning strategies. In learning, a teacher is required to be able to develop various competencies that exist in him. So it is hoped that the increased competence will create a more interesting learning atmosphere. If in teaching the teacher has not been able to use a variety of learning methods, it is feared that students' interest in economic lessons will decrease. The purpose of this study was to determine the Supervision Role of Madrasah Principals and Teacher Academic Qualifications in Teacher Competencies in Jakarta. The method used is descriptive with a qualitative approach, the results of the study say that the implementation of academic supervision by the principal can be carried out in three stages, namely: conducting pre-academic supervision, implementing class visits, and discussing the results of class visits. The implementation of an effective program of academic supervision is to achieve the required quality that requires serious supervision by the principal. Obstacles in implementing academic supervision by the principal in improving teacher performance are not enough time for supervisors to supervise and seem to be in a hurry to carry out academic supervision. When viewed from its effectiveness, the time for implementing academic supervision can be carried out every month, but the time is not sufficient, so the principal supervises the teacher every quarter or in one semester, only two supervision can be carried out.
\end{abstract}

Keywords: Role, Supervision, Qualification, Academic, Competence.

\section{ABSTRAK}

Rendahnya kompetensi guru di Indonesia dapat dilihat dari kelayakan guru mengajar. Bukti rendahnya profesionalitas guru juga dapat terlihat dari masih banyaknya guru yang tidak menguasai berbagai kompetensi. Misalnya saja masih banyak guru mengalami kendala dalam menerapkan berbagai strategi pembelajaran. Dalam pembelajaran, seorang guru dituntut untuk mampu mengembangkan berbagai kompetensi yang ada pada dirinya. Sehingga diharapkan dengan peningkatan kompetensi tersebut akan menciptakan suasana belajar yang lebih menarik. Jika dalam mengajar ternyata guru belum mampu menggunakan variasi metode pembelajaran, maka dikhawatirkan minat siswa terhadap pelajaran ekonomi akan berkurang. Tujuan penelitian ini adalah untuk mengetahui Peran Supervisi Kepala Madrasah dan Kualifikasi Akademik Guru dalam Kompetensi Guru di Jakarta. Metode yang digunakan adalah Deskriptif dengan pendekatan Kualitatif, hasil penelitian menunjukan bahwa dalam pelaksanaan supervisi akademik oleh kepala sekolah dapat dilakukan dalam tiga tahap yaitu: melakukan pra supervisi akademik, pelaksanaan kunjungan kelas, dan pembahasan hasil kunjungan kelas. Pelaksanaan program efektif supervisi akademik adalah untuk mencapai kualitas yang dipersyaratkan perlu mendapat pengawasan yang sungguh-sungguh oleh kepala sekolah. Hambatan dalam pelaksanaan supervisi akademik oleh kepala sekolah dalam meningkatan komperensi guru yaitu: tidak tersedianya waktu yang cukup bagi supervisor untuk melakukan supervisi dan terkesan terburu-buru dalam melaksanakan supervisi akademik. Bila dilihat dari efektivitasnya, waktu pelaksanaan supervisi akademik dapat dilakukan tiap bulan, namun waktu tidak mencukupi maka kepala sekolah mensupervisi guru tiap triwulan atau dalam satu semester dapat dilakukan cuma dua supervisi.

Kata kunci: Peran, Supervisi, Kualifikasi, Akademik, Kompetensi.

1. PENDAHULUAN
Dalam proses belajar-mengajar di kelas guru memegang peranan yang sangat 
penting. Penyelenggaraan pendidikan di sekolah sangatlah menentukan mutu pendidikan (Lalupanda, 2019).

Para siswa tetap memerlukan bimbingan dan arahan untuk dapat belajar dengan baik. Untuk menjadi seorang guru yang profesional, dituntut untuk memahami dan menerapkan berbagai media pembelajaran di dalam proses belajar mengajar di dalam kelas. Selain itu, media pembelajaran yang bervariasi dapat membantu siswa mengembalikan semangat belajarnya (Astuti, 2017). Di samping itu, media pembelajaran yang bervariasi membuat para siswa tertarik dan tertantang untuk mengikuti proses pembelajaran tanpa membuat siswa tersebut jenuh dan bosan dalam mengikuti proses balajar-mengajar tersebut. Oleh karena itu, variasi media pembelajaran di madrasah dasar sangat diperlukan, apalagi keadaan siswa madrasah dasar yang pola pikirnya masih bersifat konkret dan masih senang bermain, sangat cocok diterapkan media pembelajaran yang bervariasi. Para guru hendaknya membuat pembelajaran jadi bermakna dan buatlah semua siswa aktif dalam mengikuti proses belajar-mengajar, jangan gurunya saja yang aktif dalam proses pembelajaran.

Rendahnya kompetensi guru di Indonesia dapat dilihat dari kelayakan guru mengajar. Bukti rendahnya profesionalitas guru juga dapat terlihat dari masih banyaknya guru yang tidak menguasai berbagai kompetensi. Misalnya saja masih banyak guru mengalami kendala dalam menerapkan berbagai strategi pembelajaran. Dalam pembelajaran, seorang guru dituntut untuk mampu mengembangkan berbagai kompetensi yang ada pada dirinya. Sehingga diharapkan dengan peningkatan kompetensi tersebut akan menciptakan suasana belajar yang lebih menarik. Jika dalam mengajar ternyata guru belum mampu menggunakan variasi metode pembelajaran, maka dikhawatirkan minat siswa terhadap pelajaran ekonomi akan berkurang.

Metode pembelajaran harus bervariasi supaya siswa tidak jenuh dan dapat menikmati pembelajaran. Salah satu usaha untuk meningkatkan profesionalisme guru, dilakukan melalui supervisi akademik kepala madrasah dalam supervisi kinerja guru. Keberadaan kepala madrasah dapat membantu guru dalam melaksanakan tugasnya, sebab kepala madrasah yang profesional, salah satunya akan mampu melakukan supervisi terhadap guru-gurunya, sehingga diduga akan dapat memperbaiki situasi proses belajar-mengajar yang berdampak positif terhadap peningkatan kualitas pendidikan (Fathurrohman \& Sutikno, 2009). Kepala madrasah merupakan figur yang menjadi contoh dan panutan bagi para guru dan para siswa dalam hal pembentukan karakter baik dalam hal disiplin, maupun dalam hal etika dan moral. Terlebih lagi saat ini telah menerapkan kurikulum baru yang berorientasi pada pembentukan karakter siswa. Memberikan pengetahuan tentang etika pergaulan, penanaman nilainilai agama, moral, budi pekerti serta etika bagi anak didik, harus terus menerus dilakukan. Di samping itu diperlukan juga kesiapan mental dan ketangguhan karakter untuk mereduksi dampak negatif dari keterbukaan informasi (Tobari, 2014). 
Guru juga membutuhkan supervisi yang bersifat kunjungan kelas, sehingga guru bisa mendapatkan masukan mengenai cara mengajarnya apakah sudah baik atau masih ada beberapa hal yang perlu ditingkatkan. Ataukah sudah sesuai dengan kurikulum yang saat ini sedang diterapkan atau belum. Karena menurut perbincangan peneliti dengan beberapa guru, mereka menyatakan bahwa kepala madrasah masih sangat jarang melakukan supervisi yang bersifat kunjungan kelas. Supervisi yang dilakukan kepala madrasah hanya bersifat administratif saja karena yang dinilai hanyalah perangkat mengajarnya. Jika perangkat mengajar sudah lengkap, maka biasanya penilaian kepala madrasah juga sudah baik.

Selain pentingnya masalah supervisi kepala madrasah masih ada hal-hal yang sekiranya akan mempengaruhi kompetensi guru, yakni kualifikasi mengajar guru. Guru yang bermutu baik merupakan dasar bagi madrasah yang baik. Madrasah yang baik merupakan landasan bagi terciptanya masyarakat yang madani dan negara yang maju. Dengan demikian, guru yang bermutu merupakan aset bagi suatu bangsa untuk mempersiapkan sumberdaya manusia yang dapat bermitra sejajar dengan negara maju di era persaingan global. Guru yang bermutu merupakan penentu terbesar bagi pencapaian prestasi siswa (Mulyasa, 2009). Karena guru sebagai penentu utama dalam menciptakan mutu pendidikan, maka peningkatan pengetahuan dan kemampuan guru merupakan investasi yang penting untuk suatu negara (Rustaman et al., 2005). Uno mengemukakan kompetensi adalah pengetahuan, ketrampilan, dan nilai-nilai yang direfleksikan dalam kebiasaan berpikir dan bertindak (Uno \& Lametanngo, 2014). Suyanto mengatakan kompetensi adalah sebuah perilaku rasional untuk mencapai tujuan yang dipersyaratkan sesuai dengan kondisi yang diharapkan (Suyanto \& Jihad, 2013).

Sudjana melihat kompetensi sebagai gabungan dari kemampuan, pengetahuan, kecakapan, sikap, sifat, pemahaman, apresiasi dan harapan yang mendasari karakteristik seseorang untuk berunjuk kerja dalam menjalankan tugas atau pekerjaan guna mencapai standar kualitas dalam pekerjaan nyata (Sudjana, 2011). Nurhayati mengatakan dalam penelitiannya memperoleh hasil yaitu secara parsial supervisi kepala madrasah maupun kualifikasi akademik guru mempengaruhi kompetensi guru. Walau pun demikian secara simultan hanya supervisi kepala madrasah yang mempengaruhi kompetensi akademik (Nurhayati, 2013). Sedangkan penelitian Syakirah menyatakan bahwa kualifikasi akademik berpengaruh secara kuat dan signifikan terhadap kompetensi guru (Syakirah, 2013).

Keberhasilan mutu pendidikan di sekolah tidak hanya ditentukan oleh guru yang berkualitas/profesional, tapi juga ditentukan oleh faktor kepala sekolah yang berkualitas/profesional. Kepala sekolah adalah pemimpin pendidikan tingkat satuan pendidikan yang harus memiliki dasar kepemimpinan yang kuat. Kepala sekolah merupakan komponen yang paling berpengaruh terhadap terciptanya proses dan hasil pendidikan yang berkualitas. Oleh karena itu, upaya perbaikan apapun yang dilakukan untuk meningkatkan kualitas 
pendidikan tidak akan memberikan sumbangan yang signifikan tanpa didukung oleh kepala sekolah yang profesional dan berkualitas. Menteri Pendidikan telah menetapkan bahwa ada 5 dimensi kompetensi yang perlu dimiliki kepala sekolah, yaitu Kepribadian, Manajerial, Kewirausahaan, Supervisi dan Sosial (PERATURAN MENTERI PENDIDIKAN NASIONAL REPUBLIK INDONESIA NOMOR 13 TAHUN 2007, 2007). Kepala sekolah dalam aktivitas kerjanya harus berkualitas dan teruji kualifikasinya (Alamsyah et al., 2020).

Berdasarkan latar belakang permasalahan di atas, peneliti tertarik untuk mengetahui lebih dalam tentang peran Supervisi Kepala Madrasah dan Kualifikasi Akademik Guru dalam Kompetensi Guru di Jakarta.

\section{KAJIAN LITERATUR}

Penelitian yang dilakukan oleh Hadi, Tukiran dan Yuwono bertujuan untuk mengetahui dampak pengawasan akademik, kompetensi guru, dan disiplin terhadap kinerja guru SMA Negeri 3 Slawi, Tegal. Penelitian ini menggunakan metode survei. Data dikumpulkan dengan menggunakan kuesioner dan observasi. Ada 52 guru sebagai responden. Analisis data yang digunakan adalah persentase, regresi linier berganda, uji F dan uji t. Temuan tersebut adalah: 1) supervisi akademik, kompetensi guru dan disiplin guru SMA 3 Slawi sangat baik, 2) supervisi akademik, kompetensi guru, dan disiplin bersama berdampak pada kinerja guru, 3) supervisi akademik, kompetensi guru, dan disiplin. Secara terpisah berdampak pada kinerja guru, dan 4) disiplin memiliki dampak paling kuat terhadap kinerja guru. Dengan hasil ini disarankan agar Dinas Pendidikan masing-masing daerah mengintensifkan pengawasan akademik, terus mengembangkan kompetensi guru dan menegakkan disiplin pada guru (Hadi et al., 2019).

Penelitian yang dilakukan oleh Awe, yoman Dantes, Lasmawan bertujuan untuk mengetahui hubungan antara kualifikasi akademik, kompetensi, motivasi kerja dengan kinerja guru madrasah dasar (SD) di kecamatan Bajawa, kabupaten Ngada. Populasi penelitian ini adalah seluruh guru madrasah dasar di Kecamatan Bajawa, Kabupaten Ngada yang berjumlah 366 orang. Sesuai dengan tabel Krejcie dan Morgan serta formula Wenwich banyaknya anggota sampel adalah 188 orang. Pengambilan sampel dilakukan dengan teknik random sampling. Penelitian ini menggunakan rancangan ex-post facto dengan teknik korelasioanl. Data yang dikumpulkan dalam penelitian ini menggunakan kuesioner dengan mengikuti pola Likert. Untuk menguji hipotesis pertama, kedua dan ketiga di gunakan teknik analisis regresi sederhana, sedangkan untuk menguji hipotesis keempat (H4) digunakan analisis regresi berganda dan uji-F. Hasil penelitian menunjukkan bahwa: 1) terdapat hubungan yang positif dan signifikan antara kualifikasi akademik dengan kinerja guru, 2) terdapat hubungan yang positif dan signifikan antara kompetensi dengan kinerja guru, 3) terdapat hubungan yang positif dan signifikan antara motivasi kerja dengan kinerja guru, 4) terdapat hubungan yang positif dan signifikan secara bersama-sama antara kualifikasi akademik, kompetensi, motivasi kerja dengan kinerja 
guru. Dengan demikian ke tiga faktor kualifikasi akademik, kompetensi dan motivasi kerja dapat dijadikan prediktor tingkat kecenderungan kinerja guru madrasah dasar di kecamatan Bajawa, kabupaten Ngada (Awe et al., 2014).

Supervisi sangat diperlukan dalam lembaga pendidikan, karena salah satu kompetensi adalah Supervisi. Supervisi dalam lembaga pendidikan memiliki 2 aspek yaitu, supervisi akademik dan supervisi manajerial (Kristiawan, 2020). Supervisi juga memegang peranan penting dalam meningkatkan kualitas guru dalam melaksanakan pembelajaran yang lebih berkualitas (Sabandi, 2013) tetapi supervisi yang baik tidak akan terwujud tanpa adanya partisipasi dari Lingkungan yang ada disekitarnya (Sari et al., 2018).

Supervisi dipandang sebagai suatu prosedur memberi arah serta mengadakan penilaian secara kritis terhadap proses pengajaran (Babuta \& Rahmat, 2019). Pelaksanaan supervisi pada umumnya sering dilaksanakan secara dictator dan terjadwal sehingga guru merasa tidak nyaman dengan adanya supervisi (Jayanti Tanama \& Supriyanto, 2016)

Supervisi merupakan suatu usaha menstimulasi, mengkoordinasi dan membimbing secara continue pertumbuhan guru-guru di sekolah, baik secara indivisu maupun secara kolektif, agar lebih mengerti dan lebih efektif dalam mewujudkan seluruh fungsi pengajaran (Muslim, 2017).

\section{METODE PENELITIAN}

Metode penelitian ini menggunakan Pendekatan Kualitatif dengan Metode Deskriptif. Pendekatan Kualitatif memberikan keleluasaan untuk memandang fenomena sosial secara holistik. Sementara Metode Deskriptif menitik beratkan pada pemaknaan (peristiwa, proses, dan tema) secara mendalam, yang kemudian dijabarkan dalam bentuk kata maupun gambar. Dalam kata lain, metode deskriptif mempunyai tujuan untuk mendeskripsikan (menggambarkan) secara terperinci fenomena sosial tertentu (Suradika, 2000)

Pendekatan kualitatif dengan metode deskriptif dipilih karena penelitian ini hendak menggambarkan secara detail dan menginterpretasikan data yang diperoleh untuk menjelaskan Peran Supervisi Kepala Madrasah dan Kualifikasi Akademik Guru dalam Kompetensi Guru. Teknik Pengumpulan Data digunakan Wawancara, Observasi dan Dokumentasi. Teknik Penentuan Informan dengan Purposif. Teknik Analisis Data digunakan berdasarkan (Miles B. \& Michael, 1994) dan Uji Keabsahan Data digunakan Triangulasi (Moleong \& Lexy, 2004).

\section{PEMBAHASAN}

Program supervisi akademik terdiri dari program tahunan, semester dan bulanan dalam menyusun program supervisi, selalu melibatkan guru senior serta koordinasi dengan pengawas sekolah agar dapat diberikan petunjuk dan saran untuk kelancaran supervisi akademik.

Pelaksanaan supervisi oleh kepala sekolah terhadap guru sangat penting dilakukan dalam rangka meningkatkan kemampuan professional guru dan kualitas pembelajaran di sekolah, Pelaksanaan supervisi akademik oleh kepala sekolah terhadap guru sangat penting dilakukan 
dalam rangka meningkatkan kemampuan profesional guru dan meningkatkan kualitas pembelajaran melalui proses pembelajaran yang baik. Esensi supervisi akademik bukan menilai kinerja guru dalam mengelola proses pembelajaran, melainkan membantu guru mengembangkan profesionalismenya (Usman, 2016)

Supervisi yang dilakukan kepala sekolah meliputi tugas merencanakan tugas supervisi akademik terhadap guru dengan penggunaan teknik yang tepat dan juga menindaklanjuti hasil supervisi terhadap guru dalam rangka untuk meningkatkan kompetensi guru. Dan peran supervisi ini besar artinya bagi keberlangsungan peningkatan mutu pendidikan, khususnya melalui peningkatan kompetensi guru, karena memuat satu fungsi manajeman berbasis sekolah yang utuh atas seluruh komponen sekolah.

Meningat begitu pentingnya kontribusi peran supervisi kepala sekolah dalam kompetensi guru, maka diharapkan agar kepala sekolah dapat mengoptimalkan peran-peran supervisi yaitu, perencanaan, pengorganisasian, penatalaksanaan, dan pengawasan atas setiap komponen satuan pendidikan lainnya.

Memberikan insentif kepada para guru serta mengadakan supervisi professional dan administrasi, dengan adanya itu maka kinerja guru disekolah akan menjadi lebih baik

Hal ini memberikan hal positif dengan adanya supervisi kepala sekolah dalam kompetensi guru, dan terdapat konstribusi antara supervisi dan kualifikasi dengan kompetensi guru.
Tingkat keberhasilan kinerja guru dapat diketahui melalui kegiatan supervisi pendidikan yang dilakukan oleh kepala sekolah, dengan menggunakan berbagai teknik supervisi. Kegiatan supervisi yang dilakukan kepala sekolah pada dasarnya adalah sebuah pemberian bantuan atau pertolongan dalam mengembangkan situasi pembelajaran yang lebih baik di lingkungan sekolah (Hasanah et al., 2019)

Kualifikasi akademik merupakan ijazah satuan pendidikan formal jenjang pendidikan akademik yang harus dimiliki sesuai dengan jenis, jenjang dan tempat panugasan. Kualifikasi akademik yang sesuai akan menjadi modal utama dalam melaksanakan tugasnya. Suatu pekerjaan tidak akan bisa berjalan dengan maksimal jika pelaksana nya tidak memiliki kualifikasi yang sesuai, misalnya guru yang kualifikasinya non pendidikan kemudian mengajar pada bidang pendidikan. Selain guru akan mengalami kesulitan dalam proses pembelajaran, siswa pun juga tidak memperoleh pengetahuan sesuai dengan tujuan pembelajaran. Karena kualifikasi akademik yang tidak sesuai (Salamah \& Mufidah, 2019).

Dalam hal peningkatan kualifikasi pendidikan, tidak hanya berkaitan dengan kualifikasi akademik semata, akan tetapi dituntut juga penguasaan pembelajarannya, mulai dari merencanakan, melaksanakan dan mengevaluasi pembelajaran mencakup seluruh jenis dan kompetensi (Mimpira Haryono, 2020)

Dalam perspektif kebijakan pendidikan nasional terdapat tujuh peran utama kepala sekolah yaitu: 
1. Educator (Pendidik).

2. Manajer.

3. Administrator.

4. Supervisor (Penyelia).

5. Leader (Pemimpin).

6. Pencipta Iklim Kerja.

7. Wirausahawan.

Dan sejauh mana kepala sekolah dapat mewujudkan peran peran di atas, secara langsung maupun tidak langsung dapat memberikan kontribusi terhadap peningkatan kompetensi guru, yang pada dasarnya dapat meningkatkan efek terhadap peningkatan mutu pendidikan di sekolah (PERATURAN

MENTERI PENDIDIKAN NASIONAL REPUBLIK INDONESIA NOMOR 13 TAHUN 2007, 2007)

\section{PENUTUP}

\section{- KESIMPULAN}

Hambatan yang dihadapi kepala sekolah dalam menyusun program efektif supervisi akademik adalah masih ditemukan guru-guru yang yang tidak siap untuk disupervisi, padahal kepala sekolah sudah diberitahukan jadwal supervisi agar guru dapat melakukan persiapan baik dalam penyusunan perencanaan maupun proses pembelajaran.

Dalam pelaksanaan supervisi akademik oleh kepala sekolah dapat dilakukan dalam tiga tahap yaitu: melakukan pra supervisi akademik, pelaksanaan kunjungan kelas, dan pembahasan hasil kunjungan kelas. Pelaksanaan program efektif supervisi akademik adalah untuk mencapai kualitas yang dipersyaratkan perlu mendapat pengawasan yang sungguhsungguh oleh kepala sekolah.

Hambatan dalam pelaksanaan supervisi akademik oleh kepala sekolah dalam meningkatan kinerja guru yaitu: tidak tersedianya waktu yang cukup bagi supervisor untuk melakukan supervisi dan terkesan terburu-buru dalam melaksanakan supervisi akademik. Bila dilihat dari efektivitasnya, waktu pelaksanaan supervisi akademik dapat dilakukan tiap bulan, namun waktu tidak mencukupi maka kepala sekolah mensupervisi guru tiap triwulan atau dalam satu semester dapat dilakukan cuma dua supervisi.

Kepala sekolah melakukan evaluasi pelaksanaan program efektif, meliputi evaluasi terhadap uraian tugas dan evaluasi bukti-bukti dokumen, dengan cara melihat langsung terhadap bukti-bukti tugas yang telah dilaksanakan oleh guru kemudian memberikan masukan apabila terdapat kesalahan atau kurang sesuai dengan kriteria yang diharapkan. Penilaian kinerja kepala sekolah membutuhkan standar pengukuran, cara penilaian dan analisa data hasil pengukuran, serta tindak lanjut atas hasil pengukuran.

Hambatan supervisi akademik yang dihadapi kepala sekolah dalam meningkatkan kinerja guru yaitu: tidak mempunyai waktu yang cukup dalam mengevaluasi, sehingga guru-guru tidak sempat memperbaiki kekurangannya. Sedangkan upaya yang dilakukan oleh kepala sekolah dalam menyikapi masalah tersebut tidak tersedia waktu yang cukup yaitu dengan mengatur format instrumen supervisi akademik karena waktu yang relatif singkat.

\section{REFERENSI}

Alamsyah, M., Ahmad, S., \& Harris, H. (2020). Pengaruh Kualifikasi Akademik dan Pengalaman Mengajar 
terhadap Profesionalisme Guru. In Journal of Education Research (Vol. 1, Nomor 3).

Astuti, S. (2017). Supervisi Akademik untuk Meningkatkan Kompetensi Guru di SD Laboratorium UKSW. Scholaria : Jurnal Pendidikan dan Kebudayaan, $7(1)$, https://doi.org/10.24246/j.scholaria.2 017.v7.i1.p49-59

Awe, E. Y., Dantes, N., \& Lasmawan, I. W. (2014). HUBUNGAN ANTARA KUALIFIKASI AKADEMIK, KOMPETENSI, MOTIVASI KERJA DENGAN KINERJA GURU SEKOLAH DASAR (SD) DI KECAMATAN BAJAWA, KABUPATEN NGADA. Jurnal Pendidikan Dasar Ganesha, 4. https://media.neliti.com/media/public ations/123152-ID-hubungan-antarakualifikasi-akademik-kom.pdf

Babuta, A. I., \& Rahmat, A. (2019). Peningkatan Kompetensi Pendagodik Guru melalui Pelaksanaan Supervisi Klinis dengan Teknik Kelompok. $A L$ TANZIM: JURNAL MANAJEMEN PENDIDIKAN ISLAM, 3(1), 1-28. https://doi.org/10.33650/altanzim.v3i1.496

Fathurrohman, P., \& Sutikno, M. S. (2009). Strategi Belajar Mengajar; Strategi Mewujudkan Pembelajaran Bermakna Melalui Penanaman Konsep Umum \& Konsep Islami. PT Refika Aditama.

Hadi, S., Tukiran, \& Yuwono, B. (2019). PENGARUH SUPERVISI
AKADEMIK, KOMPETENSI GURU, DAN KEDISIPLINAN TERHADAP KINERJA GURU. Khazanah Pendidikan, 2(1). https://doi.org/10.31227/osf.io/e3kmu

Hasanah, M. L., Batusangkar, I., \& Kristiawan, M. (2019). Supervisi Akademik dan Bagaimana Kinerja Guru. TADBIR: Jurnal Studi Manajemen Pendidikan, 3(2), 97112.

https://doi.org/10.29240/jsmp.v3i2.11 59

Jayanti Tanama, Y., \& Supriyanto, A. (2016). Implementasi Supervisi Klinis dalam Meningkatkan Profesionalisme Guru. In Jurnal Pendidikan: Teori, Penelitian, dan Pengembangan (Vol. 1, Nomor 11). https://doi.org/10.17977/JP.V1I11.81 27

PERATURAN MENTERI PENDIDIKAN NASIONAL REPUBLIK INDONESIA NOMOR 13 TAHUN 2007, (2007) (testimony of Kementrian Pendidikan Nasional Repubik Indonesia).

Kristiawan, M. (2020). Supervisi Pendidikan (Y. Yuniarsih (ed.)). Alfabeta. https://doi.org/10.31227/osf.io/4udnj

Lalupanda, E. M. (2019). Implementasi supervisi akademik untuk meningkatkan mutu guru. Jurnal Akuntabilitas Manajemen Pendidikan, $\quad 7(1), \quad$ 62-72. https://doi.org/10.21831/amp.v7i1.22 276

Miles B., M., \& Michael, A. H. (1994). Qualitative Data Analysis: An 
Expanded Sourcebook. SAGE

Publications.

Mimpira Haryono, Y. H. (2020). Peran Kepala Sekolah Dalam Meningkatkan Kualifikasi Akademik Guru PAUD Pada Gugus Mawar Kecamatan Talo Kabupaten Seluma. Indonesian Education Administration and Leadership Journal (IDEAL), 02, 2333.

Moleong, \& Lexy, J. (2004). Metodelogi Penelitian. Remaja Rosdakarya.

Mulyasa. (2009). Implementasi Kurikulum

Tingkat Satuan Pendidikan Kemandirian Guru Dan Kepala Sekolah. Jakarta : Bumi Aksara.

Muslim. (2017). Peran Supervisi Pengawas Madrasah dalam Meningkatkan Mutu Pendidikan: Studi pada Madrasah Aliyah Negeri 3 Kabupaten Tasikmalaya. Indonesian Journal of Education Management and Administration Review, 1(1), 55.

Nurhayati, S. (2013). Upaya Peningkatan Kompetensi Guru dengan Supervisi Akademik di Madrasah Ibtidaiyah Yaspuri Lowokwaru Malang. Jurnal Pendidikan, 1(1), 48-52. https://unimuda.ejournal.id/jurnalpendidikan/article/vie $\mathrm{w} / 137$

Rustaman, N., Dirdjosoemarto, S., Yudianto, S. A., Achmad, Y., Subekti, R., Rochintaniawati, D., \& Nurjhani, M. (2005). Strategi Belajar Mengajar Biologi. UM press.

Sabandi, A. (2013). Supervisi Pendidikan untuk Pengembangan Profesionalitas
Guru Berkelanjutan. In Pedagogi: Jurnal Ilmu Pendidikan (Vol. 13, Nomor 2).

Salamah, U., \& Mufidah, N. (2019). Pengembangan Profesionalisme Guru Melalui Kualifikasi Akademik dan Kompetensi Akademik. International Conference on ..., 5458.

Sari, D. N. A., Bafadal, I., \& Wiyono, B. B. (2018). Pelaksanaan Supervisi Manajerial dalam Rangka Implementasi Manajemen Berbasis Sekolah. Jurnal Administrasi dan Manajemen Pendidikan, 1(2), 213221.

https://doi.org/10.17977/um027v1i22 018 p213

Sudjana, N. (2011). Penilaian Hasil Proses Belajar Mengajar (Edisi ke-16). In Sinarbaru. Remaja Rosdakarya.

Suradika, A. (2000). Metode Penelitian Sosial. UMJ Press.

Suyanto, \& Jihad, A. (2013). Menjadi Guru Profesional: Strategi Meningkatkan Kualifikasi dan Kualitas di Era Global (R. Fauzana (ed.)). Esensi.

Syakirah, N. S. M. (2013). Pengaruh Kualifikasi Akademik Terhadap Kompetensi Profesional Guru Produktif Program Administrasi Perkantoran Di SMK Negeri 11 Bandung Dan SMK Pasundan 1 Bandung. Universitas Pendidikan Indonesia.

Tobari. (2014). MEMBANGUN BUDAYA ORGANISASI PADA INSTANSI PEMERINTAHAN. 
Uno, H. B., \& Lametanngo, N. (2014). Teori Kinerja dan Pengukurannya. Bumi Aksara.

Usman, N. (2016). EFEKTIVITAS PELAKSANAAN SUPERVISI AKADEMIK OLEH KEPALA SEKOLAH DALAM MENINGKATKAN KINERJA GURU DI SMK NEGERI 1 MEULABOH. Jurnal Administrasi Pendidikan: Program Pascasarjana Unsyiah, 4(3). 